\title{
Achei a Palavra: Um objeto de aprendizagem colaborativo para apoiar a alfabetização
}

\author{
Jonnathann Silva Finizola ${ }^{1}$, Ayla Dantas ${ }^{1}$, Rafaelly Santana ${ }^{1}$, Thamires Neves ${ }^{1}$ \\ ${ }^{1}$ Universidade Federal da Paraíba (UFPB) - Campus IV \\ Caixa Postal 58297-000 - Rio Tinto - PB - Brasil \\ \{jonnathann.finizola, ayla, rafaelly.santana, \\ thamires.oliveira\}@dce.ufpb.br
}

Resumo. Esse trabalho apresenta o projeto, desenvolvimento e avaliação de um OA Web intitulado Achei a Palavra (AaP), além de sua comparação com OAs semelhantes utilizados no processo de alfabetização, apontando seus pontos fortes e fracos. Esse OA apresenta características de jogos, uma vez que ele é inspirado no jogo da Forca, e propõe que seu usuário adivinhe as letras que compõem uma certa palavra que é apresentada como desafio do jogo. Isso proporciona ao aluno uma ferramenta com a qual ele possa interagir aprendendo as palavras de forma divertida. Os desafios são ilustrados por imagens e áudios relativos às palavras e que podem ser cadastrados por professores de maneira colaborativa explorando diferentes contextos.

Palavras-chave: objetos de aprendizagem, jogos educativos, processo de alfabetização.

Abstract: This paper presents the design, development and evaluation of a Web Learning Object (LO) called "Achei a Palavra" (AaP). Besides, we present a comparison with other similar LO that are being used in the literacy process, pointing out its strengths and drawbacks. The AaP LO presents game features, as it is inspired by the game of hangman, and proposes that its users should guess the letters of a particular word that is presented as the challenge of the game. This gives the student a tool with which she can interact to learn the words in a fun way. The challenges are illustrated by images and audios regarding the words and they can be included by teachers in a collaborative way, exploring different contexts.

Keywords: learning objects, educational games, literacy process.

\section{Introdução}

Devido ao avanço da tecnologia, a popularização da Internet e a crescente utilização das TICs (Tecnologias de informação e Comunicação) no âmbito educacional, diversas ferramentas para o apoio da aprendizagem vêm sendo criadas com o objetivo de facilitar, servir como material de apoio ou até mesmo testar os conhecimentos do aluno sobre um determinado assunto específico. Essas ferramentas podem ser construídas na forma de animações, hipertextos eletrônicos e interativos, jogos educacionais, ou seja, qualquer sistema ou software que tenha um propósito educacional. Um aspecto importante dessas ferramentas é que possam proporcionar ao usuário/aluno um ambiente que lhes permita revisar conteúdos estudados, testar os conhecimentos através de exercícios interativos, colaborativos e também servir como material complementar que possa ser sugerido pelo professor.

Quando um sistema é desenvolvido com um propósito educacional, ele é chamado de Objeto de Aprendizagem ou, abreviadamente, OA. Segundo uma pesquisa realizada no centro de estudos sobre Tecnologia de Informação e de Comunicação (Cetic, 2012), a utilização dessas ferramentas no âmbito educacional tem crescido consideravelmente, o que leva a crer que essas ferramentas estão tendo um papel 
importante dentro da estratégia de ensino do professor e de estudo do aluno. Mas mesmo com todo esse avanço tecnológico de desenvolvimento e utilização de OAs no âmbito educacional, existem poucos deles voltados à alfabetização que tenham características que tornem o OA divertido para o aluno e que estão presentes em jogos voltados ao entretenimento. Muitos dos objetos existentes, devido à falta de um bom planejamento no seu desenvolvimento, acabam se tornando monótonos e fazendo com que o aluno perca o interesse logo nos primeiros momentos em que ele interage com o OA. Outros, apesar de interessantes, não são bem contextualizados com o que está sendo trabalhado em sala de aula, sendo estes os fatores principais que motivaram o desenvolvimento deste trabalho.

Vários estudos mostram a popularidade dos jogos e sua capacidade de motivar a ação, a resolução de problemas e de potencializar o processo de aprendizagem nas mais diversas áreas de conhecimento e da vida dos indivíduos (Papert, 2008). Acredita-se que jogos possibilitam tornar um ambiente que antes era monótono em um ambiente divertido. Considerando a sociedade atual, são cada vez mais populares os jogos eletrônicos, os quais são construídos para divertir os jogadores, prendendo sua atenção. Se utilizados no contexto educacional, podem auxiliar no aprendizado de conceitos, conteúdos e habilidades presentes nesses jogos, estimulando assim a autoaprendizagem, a descoberta, a curiosidade e a fantasia (Silveira, 1998). Considerando esses aspectos, torna-se pertinente desenvolver um OA que envolva o processo de alfabetização, mas que também compreenda um contexto familiar ao aluno e que o desafie (An et.al, 2013). É nesses termos que o objetivo desse trabalho é apresentar o projeto e desenvolvimento de um OA intitulado Achei a Palavra (AaP) e compará-lo com OAs semelhantes que podem ser utilizados no processo de alfabetização, além de apontar seus pontos fortes e fracos e avaliar seu nível de aceitação. Esse OA apresenta características de jogos, uma vez que ele é inspirado no jogo da Forca, em que seu usuário deve adivinhar as letras que compõem uma certa palavra, apresentada como desafio do jogo. Isso proporciona ao aluno uma ferramenta com a qual ele possa interagir aprendendo e conhecendo as palavras de forma divertida. Os desafios são ilustrados por imagens e áudios relativos às palavras que constituem a base de palavras a serem adivinhadas. Essa base de dados multimídia é construída de forma colaborativa, o que é um diferencial no OA proposto e permite que o professor possa melhor inseri-lo em seu planejamento.

As demais seções do presente artigo estão organizadas da seguinte forma: na Seção 2 é apresentada a metodologia utilizada para o desenvolvimento desse trabalho, na Seção 3 é apresentado o referencial teórico, na Seção 4 são apresentados jogos relacionados ao OA proposto, na Seção 5 é apresentada a descrição do OA proposto, na Seção 6 é apresentada uma avaliação do OA, e na Seção 7 são apresentadas as conclusões e sugestões de trabalhos futuros.

\section{Metodologia}

O tipo de pesquisa utilizada para a realização desse trabalho é de caráter exploratório, pois tem como objetivo proporcionar um maior conhecimento sobre o assunto, desenvolver, esclarecer e modificar conceitos e ideias, tendo em vista a formulação de problemas mais precisos ou hipóteses pesquisáveis para estudos posteriores (Gil, 1999). Esse tipo de pesquisa foi escolhido justamente para tentar responder à seguinte questão de pesquisa:

i) Como poderia ser projetado um objeto de aprendizagem para apoiar o processo de alfabetização que seja divertido e de base de dados construída colaborativamente?

Para o desenvolvimento desse trabalho foram seguidas algumas etapas para que 
se chegasse ao projeto do OA Achei a Palavra. O primeiro passo foi realizar um levantamento bibliográfico sobre trabalhos desenvolvidos relacionados ao uso de OAs para apoiar o processo de alfabetização. O segundo passo foi pesquisar na Internet objetos de aprendizagem existentes e que podem ser utilizados no processo de alfabetização. Durante essa pesquisa foram analisados os seus pontos fortes e fracos, e o que poderia ser melhorado e considerado no projeto e desenvolvimento do OA proposto nesse trabalho, que foi sendo desenvolvido de maneira iterativa e incremental, sendo avaliado por profissionais por meio de um estudo de caso.

\section{Referencial Teórico}

Segundo Martins et al. (2015), as novas tecnologias abrem espaços e possibilidades no trabalho docente, principalmente quando a Internet é explorada, já que ela permite romper as fronteiras do tempo e do espaço, proporcionando a ampliação do conhecimento e da comunicação, através da agilidade e dinamismo na manipulação de conteúdos a serem pesquisados ou estudados em sala de aula. Essas tecnologias têm sido bastante exploradas na construção de OAs.

Segundo Tarouco (2016), os objetos de aprendizagem são recursos digitais usados para apoiar a aprendizagem. Alguns exemplos de objetos de aprendizagem são as simulações, as calculadoras eletrônicas, as animações, os tutoriais, os textos, os sites www, os clips de áudio e vídeo, as ilustrações, os diagramas, os mapas, os jogos, entre outros.

Acredita-se que por meio dos jogos e seus elementos as crianças podem desenvolver noções de equilíbrio, de formas, de espaço, dentre outras habilidades. Além disso, os jogos são veículos de expressão e socialização das práticas culturais, além de serem também uma atividade lúdica em que crianças ou adultos se engajam em um mundo imaginário, regido por regras próprias que geralmente são construídas a partir das próprias regras sociais de convivência (Didático, 2009, p.9).

A alfabetização é a ação de alfabetizar, de tornar alfabeto, ou seja, é ação de fazer com que um analfabeto, aquele que não conhece o alfabeto, conheça-o e o utilize no processo de leitura e escrita (Soares, 2009).

Segundo Freire (2003, p. 13), "A alfabetizaçao é a criação ou a montagem da expressão escrita da expressão oral". Segundo Nogueira et al. (2010, p. 1), a alfabetização "é uma das etapas mais importantes de todo o processo educacional de um indivíduo e qualquer forma de facilitar o aprendizado é amplamente bem vinda." Como é um processo na maioria das vezes voltado às crianças, os jogos podem ser poderosos aliados para que essas crianças possam refletir sobre o sistema de escrita, sem, necessariamente serem obrigadas a realizar treinos enfadonhos e muitas vezes sem sentido para elas. Nos momentos de jogo, as crianças mobilizam saberes acerca da lógica de funcionamento da escrita, consolidando aprendizagens já realizadas ou se apropriando de novos conhecimentos nessa área. Brincando, elas terão a possibilidade, de forma lúdica, de compreender os princípios de funcionamento do sistema alfabético e podem socializar os seus saberes com os de seus colegas de classe (Didático, 2009, p.13).

\section{Jogos Relacionados}

Atualmente existem alguns jogos digitais que podem ser utilizados para apoiar a alfabetização e que são, portanto, relacionados a esse trabalho. Um dos jogos relacionados é o jogo online da Forca, disponível no endereço: $<$ http://www.soportugues.com.br/secoes/jogos/forca/forca.html $>$. Este jogo da forca tem por objetivo fazer o jogador encontrar a palavra secreta indicando as letras 
que ele acredita que compõem a palavra, tentando acertar com o menor número de tentativas para assim evitar que o personagem sendo "enforcado" seja desenhado por completo na forca. A medida que o jogador vai acertando as possíveis letras, ele continua o jogo, sugerindo mais letras. Caso ele vá errando, partes do personagem vão sendo desenhadas na forca: cabeça, corpo, braços, mãos, pernas e pés. A Figura 1 ilustra esse jogo.

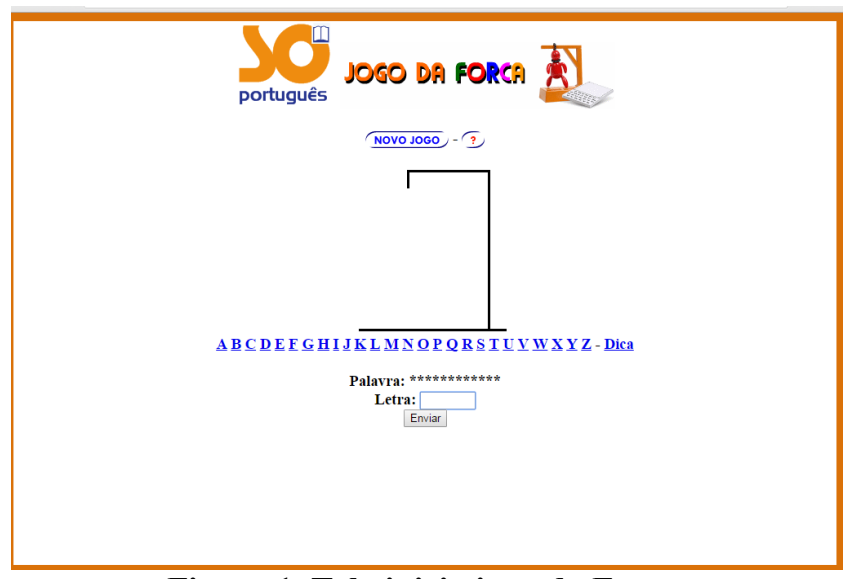

Figura 1. Tela inicia jogo da Forca.

Fonte: http://www.soportugues.com.br/secoes/jogos/forca/forca.html

Outro jogo relacionado a este trabalho é o jogo web craque das letras, disponível no endereço: http://migre.me/togGV. Este jogo tem como objetivo treinar o aluno na escrita de palavras que estão apresentadas do lado direito da tela do jogo, explorando as letras do alfabeto que assumem a forma de jogadores em um campo de futebol. $\mathrm{O}$ aluno controla a bola através do mouse direcionando-a para a letra com a qual ele deseja colidir. Quando a bola colide com determinada letra, um visor logo acima mostra a letra com a qual a bola colidiu. O objetivo do aluno é usar o raciocínio e direcionar a bola para as letras de maneira a formar palavra. A Figura 2 ilustra esse jogo.

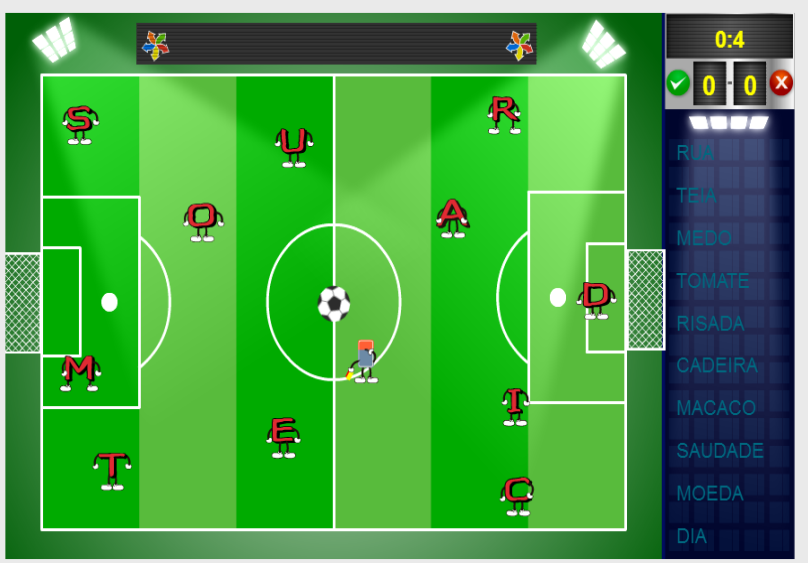

Figura 2. Tela inicial do jogo Craque da Letras. Fonte: http://migre.me/togGV

Observando esses e outros jogos existentes, percebeu-se que os desafios propostos por estes são fixos. Acreditando que é interessante que o jogo seja dinâmico considerando os desafios que possa apresentar, e acreditando também que é interessante explorar a ideia de Paulo Freire de que "Ensinar não é transferir conhecimento, mas criar as possibilidades para a sua produção ou a sua construção" (Freire, 1996, p. 21), pensou-se em uma ferramenta para apoiar a aprendizagem explorando o contexto do aluno e onde as palavras exploradas possam ser definidas com a ajuda do professor.

Considerando que os meios tecnológicos podem se tornar esses meios facilitadores para promover essa aprendizagem significativa, dentro e fora da sala de 
aula, é que está sendo proposto o OA Achei a Palavra, que apresenta como diferenciais a ideia de ter uma base de desafios construída colaborativamente e que explora recursos multimídia. Outro diferencial do jogo, não encontrado em outros OAs existentes, é a sua capacidade de poder ser executado em diferentes dispositivos, uma limitação de vários dos OAs.

\section{Descrição do OA Achei a Palavra}

O objeto de aprendizagem $\boldsymbol{A a P}$ é uma ferramenta na forma de um jogo educativo web que pode ser acessado por navegadores de diferentes tipos de dispositivo. Ele visa apoiar a alfabetização como um material complementar e ajudar os alunos de forma lúdica no aprendizado das palavras e na sua leitura. Além disso, conta com um serviço de cadastro colaborativo onde as pessoas poderão contribuir adicionando palavras, imagens e áudios. Ele é composto por alguns recursos que ajudam e motivam o aluno a querer continuar jogando e descobrindo as palavras. Um dos recursos são as imagens e áudios referentes às palavras apresentadas como desafios no OA. Este OA pode ser acessado através do endereço: http://aap.dcx.ufpb.br

As imagens e áudios são recursos importantes no processo de aprendizagem e, considerando que as crianças, jovens e adultos aprendem boa parte do que sabem através de informações visuais, percebe-se que há uma grande importância e também um grande diferencial ao utilizar recursos como vídeos, imagens e animações em objetos educacionais (Grando et al, 2003). Essas imagens presentes no OA proposto nesse trabalho servem como dicas onde o aluno após visualizá-las, tentará identificar um conjunto de possíveis letras que compõem a palavra do desafio. Ao final, ele irá aprender a escrita e também a identificar que ela refere-se à imagem apresentada. Um outro recurso presente no OA $\boldsymbol{A a P}$ é a presença de sons. Tanto os sons do alfabeto quanto os sons da palavra poderão ser escutados pelo aluno, contribuindo assim para que o aluno vá se divertindo e analisando as semelhanças sonoras de palavras que rimam ou têm sílabas iniciais iguais (Morais e Leite, 2005). Com a presença desses recursos audiovisuais, os alunos são ajudados a observar certas características do sistema alfabético como a ordem, a estabilidade e a repetição de letras nas palavras e, ao mesmo tempo, relacionando o som das letras e das palavras a imagens e áudios apresentados (Morais e Leite, 2005).

O jogo possui um recurso de customização representado por um sistema de cadastro onde, de maneira colaborativa, professores ou pessoas que convivam com a pessoa em processo de alfabetização possam cadastrar os desafios: palavras, imagens e áudios associados a essas palavras e imagens de acordo com um contexto específico que eles criarem (ex: natureza, animais, uma música em particular, etc). Também é possível fazer algumas alterações como apagar contextos ou desafios e também testar os áudios que foram cadastrados nos desafios. Esse sistema para cadastro de contextos e desafios pode ser acessado ao clicar no ícone de configurações do $\boldsymbol{A a P}$. A tela inicial (Figura 3) e tela principal do jogo (Figura 4) estão ilustradas abaixo.

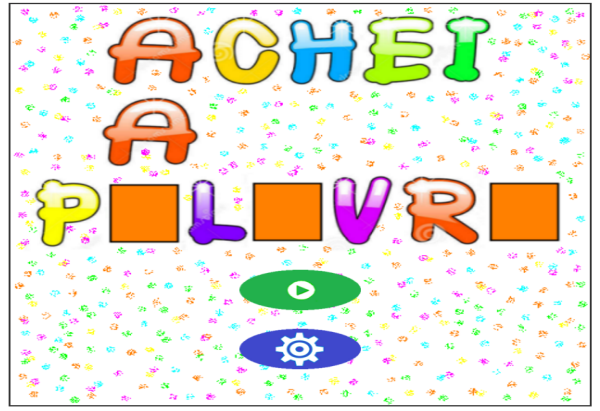

Figura 3 - Tela inicial do AaP

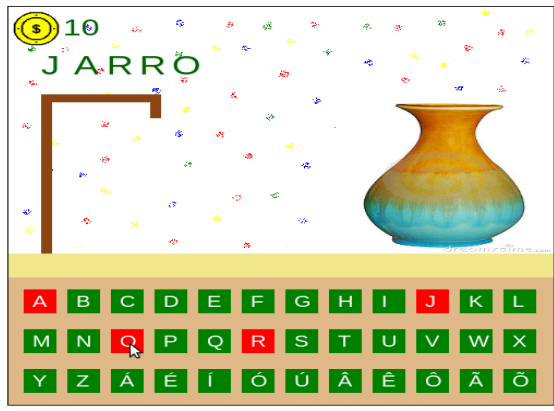

Figura 4 - Tela principal do AaP

V. $14 \mathrm{~N}^{\circ} L$, aezemoro, $\angle \mathrm{U} 10$ 
De maneira geral, o objetivo do jogador é descobrir as letras que compõem uma palavra, e que são representadas no jogo como botões verdes. Quando o jogador acerta uma letra, o som da letra é emitido e quadrados verdes mostrados na parte superior do jogo correspondentes a cada letra da palavra são substituídos por essas letras. Além disso, os botões na parte inferior da tela com as letras já escolhidas ficam vermelhos, indicando que aquelas letras já foram selecionadas de maneira correta, e ficam da cor roxa caso a letra seja selecionada incorretamente. Na medida em que o jogador vai errando as letras, partes do personagem vão sendo desenhadas na forca. Se o jogador descobrir a palavra desafio antes de todas as partes do personagem serem desenhadas na forca, a pontuação (score), representada pela moeda amarela no canto superior esquerdo é incrementada em 10 pontos.

Se todas as partes do personagem forem desenhadas na forca, o jogo reinicia e o score é zerado. É importante lembrar que ao interagir com o AaP, o jogador contará com a ajuda de uma imagem que representa a palavra escondida. Para acessar a tela principal do jogo, o jogador escolhe na tela inicial um botão na cor verde que indica "ir para o jogo". O outro botão na cor azul mostrado na tela inicial significa "customizar jogo" e permite o cadastro de contextos e desafios relacionados a esses contextos, com imagens e áudios correspondentes e que pode ser feito pelo professor.

Quando o usuário seleciona o botão verde da tela inicial, ele entrará em uma nova tela de seleção de contexto. O contexto caracteriza um grupo de desafios relacionados. Por exemplo, o contexto animais terá como desafios nomes de animais, o de cozinha terá desafios relacionados a elementos que existem na cozinha e assim por diante. Para cada contexto é mostrado um nome e uma imagem. Uma vez que seleciona o contexto, o jogador passa para uma tela em que escolherá o nível de dificuldade das palavras.

Foram considerados três níveis de dificuldade: o fácil, representado por um botão verde com uma estrela; o médio, representado por um botão amarelo; e o difícil, representado por um botão vermelho. Ao selecionar o nível dificuldade, o usuário será direcionado à tela principal do jogo com a forca. Se o usuário escolher na tela inicial a opção customizar, representada pelo botão azul, ele será direcionado ao sistema de cadastro de contextos e desafios. As telas de cadastro de contexto e de cadastro de desafios estão ilustradas pelas Figuras 5 e 6, respectivamente.

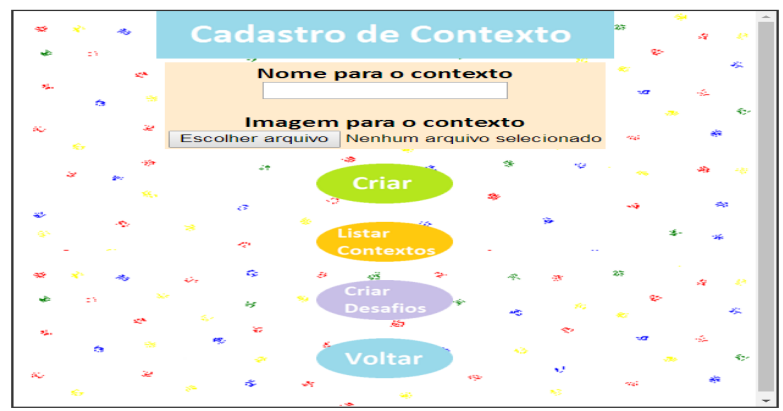

Figura 5. Tela de cadastro de contexto 


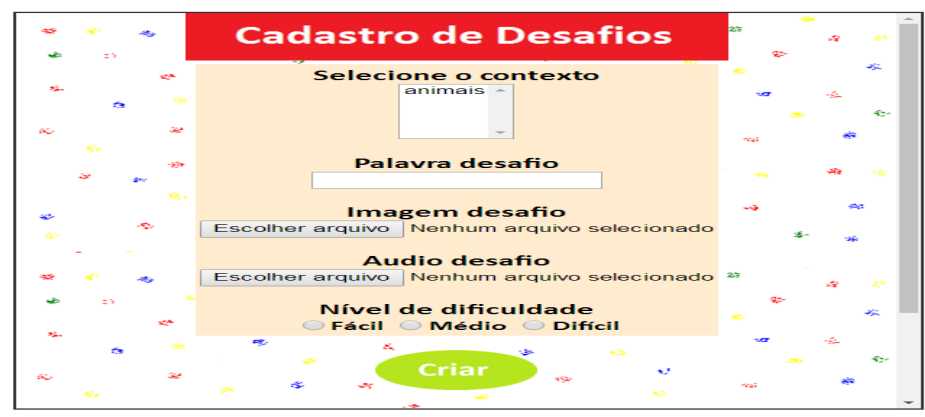

Figura 6. Tela de cadastro de desafio

Ao criar o contexto, o usuário tem a opção de poder criar os desafios e também ver, através da opção listar contextos, quais os contextos que já foram cadastrados. Se ele optar pela opção listar contextos, ele poderá também apagar os contextos desejados.

Se o usuário desejar cadastrar desafios, ele deverá digitar a palavra que represente o desafio, além de selecionar uma imagem e um áudio relacionados à palavra, bem como o nível de dificuldade: fácil, médio e difícil que ele acredita que se encaixa no desafio que está sendo cadastrado. Com o botão "Criar" ele cria o desafio com esses dados. Além disso, o usuário pode também listar os desafios já cadastrados, podendo ouvir o áudio de cada um.

O sistema foi desenvolvido utilizando as linguagens PHP, JavaScript e HTML5, como forma de permitir que possa ser utilizado por diferentes tipos de dispositivo desde que tenham acesso à Internet e um navegador.

\section{Avaliação do $\boldsymbol{A a P}$}

Nesta seção é apresentada a avaliação do AaP, tanto do ponto de vista de comparação deste OA com outros, como também uma avaliação por profissionais atuando na alfabetização.

\subsection{Avaliação Comparativa do AaP}

O OA Achei a Palavra foi comparado com outros OAs, analisando-se vantagens e desvantagens com relação a eles. Como resultado geral da análise, observou-se que o OA AaP tem algumas semelhanças e vantagens em relação aos OAs pesquisados, como os seguintes fatores: o fato de ser uma ferramenta web e rodar em praticamente todos os dispositivos, sejam eles móveis ou Desktop; a característica de apresentar uma interface amigável para o jogador em processo de alfabetização, embora seu design possa passar por melhorias com o apoio de especialistas da área de design; o fato de possuir elementos que colaboram para que o alfabetizando possa exercitar várias vezes a escrita e pronúncia correta de palavras; e também a possibilidade de oferecer desafios que são construídos de forma colaborativa, ou seja, permite-se que pessoas que tenham acesso ao sistema via Internet possam adicionar desafios, inclusive referentes a exercícios relacionados a um contexto de projeto sendo trabalhado na escola pelo professor, por exemplo. Um ponto a enfatizar é a questão do próprio professor, em sala de aula, poder utilizar a ferramenta de forma lúdica com os seus alfabetizandos, dinamizando suas aulas.

Observou-se que o Jogo da Forca Web e o Jogo Craque das Letras, que foram previamente discutidos, apresentam como pontos fortes o fato de serem também ferramentas Web. A segunda apresenta uma interface bastante amigável, inclusive. No entanto, como uma de suas limitações, observou-se que apresentam uma base de dados limitada e que não pode ser editada pelo professor, como sugerido para o OA Achei a 
Palavra. Além disso, não demonstram como as letras e palavras são pronunciadas, o que é uma outra característica do OA aqui proposto.

Embora na literatura sejam citados outros trabalhos, como o de An (2013), que apresenta o jogo Digita para auxiliar a alfabetização, pelos detalhes apresentados nestes trabalhos, acredita-se que estes também apresentem as limitações destes outros OAs apresentados quando comparados ao Achei a Palavra.

\subsection{Avaliação de Especialistas}

O jogo foi avaliado por quatro profissionais pedagogos que trabalham no processo de alfabetização de crianças e adolescentes entre 6 e 14 anos e também com jovens e adultos. Esses profissionais trabalham há mais de três anos nas escolas da Paraíba e participaram da pesquisa respondendo um questionário online ${ }^{1}$ disponibilizado através da ferramenta de criação de formulários da Google.

Avaliou-se por meio do formulário a percepção dos profissionais quanto à facilidade de uso da ferramenta e a respeito da utilidade do mecanismo de colaboração oferecido pela ferramenta, através do qual professores podem cadastrar desafios. Os resultados referentes a esta percepção estão ilustrados respectivamente pelas Figuras $7 \mathrm{e}$ 8.

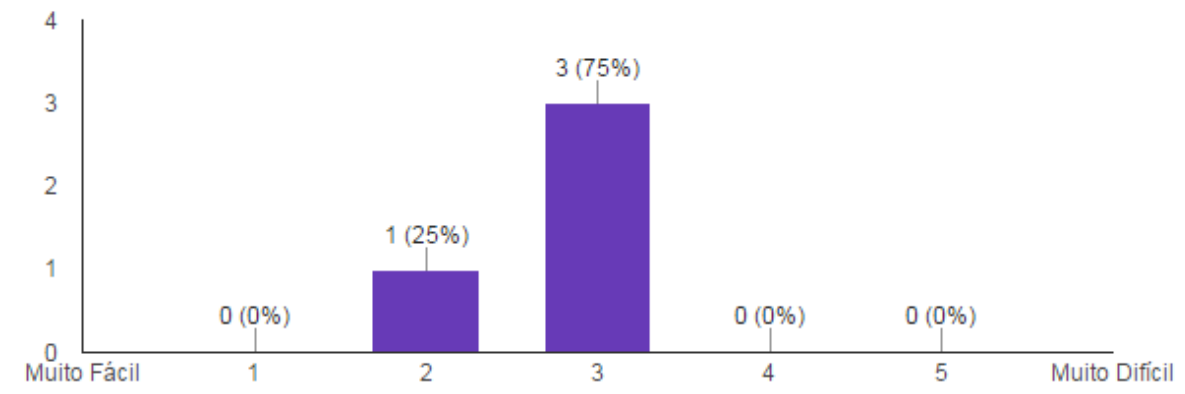

Figura 7 - Análise da percepção quanto ao nível de dificuldade da ferramenta.

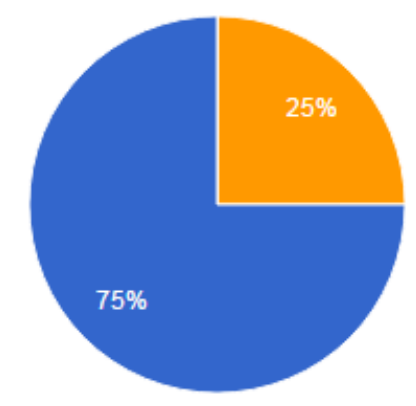

Achei muito bom, pois posso criar exercícios, cadastrá-los e interagir com os meus alunos

Não achei muito bom, pois parece ser muito complicado cadastrar os desafios e criar os contextos

Opinião Neutra (nem bom nem ruim)

Figura 8 - Análise da percepção quanto à utilidade da funcionalidade de colaboração oferecida pela ferramenta

Com relação à facilidade de uso da ferramenta, observou-se, em geral, uma neutralidade, já que a ferramenta não foi considerada nem muito fácil (1) e nem muito difícil (5), tendo $75 \%$ dos especialistas escolhido o valor 3 na escala de Likert de 1 a 5 que foi utilizada e $25 \%$ escolhido a opção 2 . Com relação à percepção da utilidade da funcionalidade de colaboração da ferramenta, $75 \%$ dos profissionais consideraram muito bom poder fazer sozinhos cadastros de novos desafios e contextos. Apenas $25 \%$ dos profissionais tiveram uma opinião neutra sobre essa funcionalidade do jogo.

Dos profissionais que avaliaram a ferramenta, três deles utilizariam o AaP para

${ }^{1}$ Link do formulário aplicado com os especialistas da área: 
uma aula diferente, enquanto apenas um não utilizaria. Quando questionados sobre se indicariam a ferramenta para colegas, todos os avaliadores responderam que recomendariam. Quando questionados sobre os pontos positivos da ferramenta, os especialistas destacaram que o fato do AaP ser um jogo torna prazeroso o aprendizado para o aluno, já que ele aprende brincando. Destacaram também que ele é prático, didático, atrativo e lúdico, pois faz associação de palavras a imagens.

Mesmo o AaP sendo uma ferramenta que possa ser utilizada em diversas plataformas, como celulares, computadores e tablets, bastando apenas que estes possuam acesso à Internet, foram identificadas pelos especialistas da área algumas limitações quanto ao seu uso quando se pediu para destacar os aspectos negativos observados. Um dos aspectos negativos levantados foi a necessidade de Internet para se utilizar o AaP já que várias escolas, como as escolas em que lecionam não possuem Internet. Outro ponto levantado foi que seria interessante que o uso com celular não fosse tão limitado como está atualmente, considerando a limitação do tamanho da tela. Apontaram que considerando a grande popularização dos smartphones seria muito interessante que o AaP fosse projetado pensando também em interfaces pequenas. Inclusive foi esta a plataforma utilizada pelos profissionais durante a avaliação.

Diante de todas as respostas que foram analisadas, ficou evidente que o AaP pode ser útil para o processo de alfabetização e que se acredita que a capacidade de ser colaborativo pode auxiliar no processo de ensino-aprendizagem, tanto das crianças como dos jovens e adultos. Além disso, viu-se que sua utilização pode contribuir também para a realização de uma aula mais dinâmica, interativa e diferente.

\section{Conclusões e Trabalhos futuros}

Esse trabalho apresentou o OA Achei a Palavra (AaP) e a comparação deste com outros OAs para apoiar o processo de alfabetização, além de sua avaliação por profissionais. Percebe-se que desenvolver ferramentas tecnológicas para apoiar a alfabetização é sempre um desafio, pois a todo momento é necessário ter um nível muito forte de empatia pelo fato de que o que está sendo construído vai ser direcionado a pessoas que não possuem conhecimento alfabético e nem têm a habilidade de leitura. Sendo assim, buscou-se explorar imagens ao máximo ao invés de textos. Observou-se que o OA proposto mostrou ter recursos superiores aos dos demais com que foi comparado e acredita-se que ele pode apoiar o processo de alfabetização do estudante, considerandose análises iniciais por especialistas, tornando o processo de exercitar a leitura mais lúdico e dinâmico e dando ao aluno um feedback imediato sobre erros e acertos.

Outro ponto a ressaltar é a possibilidade de incorporar a ferramenta ao planejamento pedagógico do professor, já que ela permite que professores colaborem, adicionando imagens e palavras correspondentes a exercícios e já que permite uma nova forma do professor interagir com os seus alunos. Contudo, observou-se que, apesar desse OA apresentar muitas vantagens em relação aos demais citados, ele ainda necessita de algumas melhorias. Um dos trabalhos futuros planejados é a melhoria da sua interface, facilitando ainda mais o cadastro de desafios e contextos, e tornando-a mais profissional em termos de design. Além disso, planeja-se fazer uma avaliação do AaP com vários professores e estudantes para melhor analisar o nível de aceitação da ferramenta e outros pontos de melhoria.

\section{Referências Bibliográficas}

AN, Ding Yih et al. Digita-um jogo educativo de apoio ao processo de alfabetização infantil. In: Anais do Simpósio Brasileiro de Informática na Educação. 2013. p. 154. 
LIKERT, R. A technique for the measurement of atitudes. Archives in Psychology, 140, p.1-55, 1932.

CETIC - Pesquisa TIC Educação 2012 - Pesquisa sobre o uso das TIC nas escolas Brasileiras. Disponível em $:<$ http://www.cetic.br/educacao/index.htm $>$. Acesso em: 26 out. 2016.

DIDÁTICO, M. Jogos de alfabetização. In: Brasília: Ministério da Educação/Secretaria de Educação Básica. Diretoria de Concepções e Orientações Curriculares para a Educação Básica. Coordenação Geral de Ensino Fundamental. 2009.

FREIRE, Paulo et al. A importância do ato de ler. Moderna, 2003.

FREIRE, Paulo. Pedagogia da autonomia: saberes necessários à prática pedagógica. São Paulo: Paz e Terra, p. 165, 1996.

GRANDO, Anita; TAROUCO, Liane Margarida Rockenbach; KONRATH, Mary Lúcia Pedroso. Alfabetização visual para a produção de objetos educacionais. RENOTE, v. 1, n. 2, 2003.

GIL, Antonio Carlos. Antonio Carlos. Como elaborar projetos de pesquisa, v. 4, 1999.

Jogo da forca. In: só português. Disponível em: $<$ http://www.soportugues.com.br/secoes/jogos/forca/forca.html $>$. Acesso em: 28 mar. 2016.

Jogo craque das letras. In: educação dinâmica. Disponível em: $<$ http://www.educacaodinamica.com.br/ed/views/game_educativo.php?id=40\&jogo $=\mathrm{Cr}$ aque\%20das\%20Letras $>$. Acesso em: 28 de março de 2016.

LIKERT, Rensis. A technique for the measurement of attitudes. Archives of psychology, 1932.

LUIZ, R. C. D. Plone 4: Administrando servidores plone 4x na prática. Disponível em: $<$ https://goo.gl/8A5nwG >. Acesso em: 28 mar. 2016.

MORAIS, Artur; LEITE, Tânia. Como promover o desenvolvimento das habilidades de reflexão fonológica dos alfabetizandos. Morais A, Albuquerque E., Ferraz T. Alfabetização: apropriação do sistema de escrita alfabética. Belo Horizonte: Autêntica, p. 71-88, 2005.

MARTINS DE OLIVEIRA, Eneida; COSTA SILVA, Bruna; ARAGÃO SÁ, Jullyana Queiroz. O USO DAS NOVAS TECNOLOGIAS NO PROCESSO DE ENSINOAPRENDIZAGEM DE LÍNGUA PORTUGUESA. Iniciação \& Formação Docente, v. 1, n. 2, 2015.

NOGUEIRA, Denise et al. Papa Letras: Um Jogo de Auxílio à Alfabetização Infantil. Simpósio Brasileiro de Jogos e Entretenimento Digital (SBGAMES), p. 170-174, 2010.

PAPERT, Seymour. A máquina das crianças: repensando a escola na era da informática. Trad. Sandra Costa. Porto Alegre: Artmed, 2008.

SOARES, Magda. Letramento: um tema em três gêneros. 3a. ed. Autêntica Editora, 2009.

SILVEIRA et al. Estudo e Construção de uma Ferramenta de Autoria Multimídia para a Elaboração de Jogos Educativos. POA-PPGC, 1999. Dissertação de Mestrado.

TAROUCO, Liane. Avaliação de objetos de aprendizagem. Disponível em: < http://penta2.ufrgs.br/edu/avaliacao/avalObjetosAprendizagem.pdf $>$. Acesso em: 10 dez. 2016. 